\title{
Tipologias e taxonomias dos prestadores de serviços logísticos: uma revisão de literatura
}

\section{Typologies and taxonomies of logistics service providers: a literature review}

Eurico Laydner Quinteiro Neto ${ }^{1}$

(D) Mônica Maria Mendes Luna ${ }^{2}$

${ }^{1}$ Universidade Federal de Santa Catarina Mestre em Engenharia de Produção com ênfase em Transportes e Logística pela Universidade Federal de Santa Catarina (2018). Atua como Cientista de Dados na empresa Aquarela Advanced Analytics. Durante o mestrado, desenvolveu pesquisas nas áreas de terceirização logística, relocalização de cadeias produtivas, logística reversa e pesquisa operacional. Bacharel em Engenharia de Transportes e Logística pela Universidade Federal de Santa Catarina (2015) elqneto@gmail.com

${ }^{2}$ Universidade Federal de Santa Catarina Doutora em Engenharia de Produção pela Universidade Federal de Santa Catarina (2003). DEA (Diplôme d'Études Approfondies) em Logística e Organizações pela Universidade Aix-Marseille II (2000), França. Mestre em Engenharia de Produção pela Universidade Federal de Santa Catarina (1996). Atualmente é Professora Associada da Universidade Federal de Santa Catarina, ministrando as disciplinas de Logística e Teoria da Decisão nos cursos de Engenharia de Produção e atuando em pesquisas na área de Planejamento de Sistemas de Logística e Transportes, Gestão da Cadeia de Suprimentos e Cadeias Reversas e Logística no contexto da Economia Circular monica.luna@ufsc.br
Resumo

A indústria de serviços logísticos tem se transformado significativamente nas últimas décadas com mudanças no perfil dos prestadores de serviços logísticos (PSL). Na literatura, propostas para classificar estas empresas podem ser identificadas em diversos trabalhos e, apesar dos autores se embasarem em critérios variados, observa-se uma tendência, nos últimos anos, para a adoção de critérios relacionados a competências de PSL. Este artigo apresenta uma revisão da literatura com o objetivo de analisar as estruturas classificatórias de PSL e os respectivos critérios propostos. Para tanto, foram identificadas 14 propostas publicadas em um intervalo de 26 anos, que incluem tanto tipologias quanto taxonomias. Os resultados permitem afirmar que critérios como "propriedade de ativos", adotados nas primeiras tipologias perdem importância ao longo do tempo enquanto a complexidade da oferta de serviços logísticos, a personalização destes serviços e a capacidade do PSL de atuar como integrador da cadeia de suprimentos ganham destaque.

Palavras-chave: Terceirização Logística. Prestadores de Serviços Logístico. Classificação.

\section{Abstract}

The logistics services industry has significantly changed in the last decades as well as the logistics service providers (LSP) profile. In the literature, proposals to classify these companies are identified in several studies. Although different criteria support the author's proposals, there is a tendency to adopt criteria related to the LSP competences in recent years. This article presents a review of the literature and aims to analyze LSP classifications structures and their criteria. To this end, 14 proposals published over a 26-year period were identified, which include both typologies and taxonomies. The results allow us to affirm that criteria such as "asset ownership", adopted in the first proposals of typologies, declined in importance over time, while complexity of the logistics services, customization of these services and LSP capacity to integrate supply chain members became more important.

Key words: Logistics Outsourcing. Logistics Service Provider. Classification. 


\section{Introdução}

Prestadores de Serviços Logísticos (PSL) são empresas que oferecem uma larga gama de serviços logísticos, desde os básicos até os mais complexos, visando atender tanto às demandas de seus clientes quanto dos demais membros das cadeias de suprimentos em que atuam. Ao longo das últimas décadas, a indústria dos PSL foi marcada por muitas mudanças, com destaque para o crescimento do número de empresas que ofertam serviços logísticos, além do aumento da variedade e escopo dos serviços oferecidos pelos PSL. Destaca-se que, no Brasil, o desenvolvimento do setor de logística teve início com a abertura econômica, a partir dos anos 90, intensificando-se com a entrada de PSL estrangeiros, mais exigentes em relação às demandas de serviços logísticos (Detoni, 2003).

A indústria de PSL e sua dinâmica têm sido objeto de pesquisas que buscam identificar tendências, descrevem a sua evolução, identificam razões que levam as empresas a terceirizar ou internalizar atividades logísticas, ou, mais recentemente, que estudam a relação entre os PSL e seus clientes, cenário que, segundo Saglietto (2013), tem atraído atenção para estudos sobre classificação de PSL.

Embora se identifique na literatura vários trabalhos que propõem estruturas de classificação dos PSL (Berglund, van Laarhoven, Sharman, \& Wandel, 1999; Bolumole, 2003; Detoni, 2003; Hertz \& Alfredsson, 2003), não há consenso ou classificação predominante sobre o tema e, além disso, são vários os critérios utilizados para diferenciar os PSL. Em virtude da diversidade de empresas, classificações tanto permitem um melhor entendimento do posicionamento destas em um mercado tão dinâmico quanto auxiliam os clientes no processo de escolha dos PSL a contratar (Detoni, 2003).

Assim, com o caráter exploratório e documental inerentes à uma revisão da literatura, o presente estudo faz uma análise das classificações propostas por diversos autores, identifica os critérios usados para embasá-las, e avalia como estes têm se modificado à medida que a indústria evolui. O trabalho tem por objetivo analisar as propostas de estruturas classificatórias de PSL na literatura, incluindo tipologias e taxonomias, de forma que as informações compiladas facilitem pesquisas futuras e contribuam para o desenvolvimento desta indústria.

O trabalho está estruturado em seis secções, incluindo esta introdutória. A segunda seção descreve os procedimentos metodológicos adotados no presente estudo. A terceira seção trata da terceirização e dos prestadores de serviços logísticos. Na quarta seção, são apresentadas as estruturas classificatórias de PSL identificadas na literatura e, na quinta seção, são analisados e discutidos os resultados obtidos. Por fim, na sexta seção, são apresentadas as considerações finais e sugestões para trabalhos futuros. 


\section{Procedimentos metodológicos}

Uma variedade de classificações de PSL pode ser encontrada na literatura, algumas desenvolvidas com base em teorias e outras embasadas em estudos empíricos, com dados primários, obtidos a partir de pesquisas ou estudos de casos, ou secundários, disponibilizados por organizações ou em publicações setoriais. Uma análise destas classificações é apresentada neste trabalho, que se caracteriza como uma revisão terciária da literatura, a qual, segundo Garousi e Mantyla (2016), tem por objetivo compilar informações relevantes de outros trabalhos de forma a facilitar pesquisas futuras. Além disso, uma revisão terciária da literatura, de acordo com (Garousi e Mantyla, 2016; Kitchenham et al., 2010), consiste em uma revisão sistemática de publicações tanto de estudos primários quanto secundários. O procedimento adotado para realização da revisão sistemática da literatura (Figura 1), com foco nos artigos que propõem algum tipo de classificação de PSL, incluiu três fases principais: i) definição das bases de dados a serem consultadas, das palavras-chave e dos comandos de busca usados na consulta; ii) análise dos artigos com base nos títulos e leitura de resumos para reduzir o portfólio de artigos, com a eliminação de artigos repetidos ou cujo escopo não possuísse relação com esta pesquisa; iii) leitura dos trabalhos e análise destes para identificação das propostas de estruturas de classificação de PSL e posterior análise das estruturas de classificação.

As bases de dados, palavras-chave utilizadas como termos de busca, período de realização da pesquisa e demais parâmetros são apresentados no Quadro 1. Importante ressaltar que estes parâmetros foram definidos a partir da leitura de artigos sobre o tema.

Quadro 1 - Parâmetros de busca

\begin{tabular}{|c|c|c|c|c|}
\hline BASES DE DADOS & Scopus & $\begin{array}{l}\text { Emerald } \\
\text { Insight }\end{array}$ & Engineering Village & $\begin{array}{l}\text { Web of } \\
\text { Science }\end{array}$ \\
\hline CAMPOS DE BUSCA & Title/Abstract/Keywords & Abstract & Subject/Title/Abstract & $\begin{array}{l}\text { Topic } \\
\text { Subject }\end{array}$ \\
\hline TIPO DE DOCUMENTO & \multicolumn{4}{|c|}{ Artigos científicos indexados em periódicos (Journal articles) } \\
\hline COBERTURA TEMPORAL & \multicolumn{4}{|l|}{ Sem delimitação temporal } \\
\hline IDIOMA & \multicolumn{4}{|l|}{ Inglês } \\
\hline PALAVRAS-CHAVES & \multicolumn{4}{|c|}{$\begin{array}{l}\text { third-party logistics OU fourth-party logistics OU logistics service provider OU } \\
\text { logistics outsourcing E classification OU category OU taxonomy OU typology OU } \\
\text { review }\end{array}$} \\
\hline $\begin{array}{l}\text { PERÍODO DE REALIZAÇÃO } \\
\text { DA PESQUISA }\end{array}$ & \multicolumn{4}{|l|}{ agosto 2016 a junho 2017} \\
\hline
\end{tabular}

Fonte: Elaborado pelos autores, 2017. 
Destaca-se que acrônimos usados para designar prestadores de serviços logísticos, tais como 3PL, 4PL, LSP, PL entre outros, não foram usados nos comandos de busca devido à possibilidade de se referirem a termos de outras áreas não relacionadas ao escopo deste trabalho. Os artigos obtidos como resultado da busca, usando os termos e operadores listados acima, totalizaram 259. A segunda etapa consistiu na eliminação dos trabalhos repetidos, o que reduziu o portfólio preliminar a um montante de 138 artigos, seguido da análise dos títulos e leitura dos resumos e documentos, resultando na seleção de 28 artigos que versavam sobre a classificação ou seleção de PSL.

Figura 1 - Procedimento de pesquisa

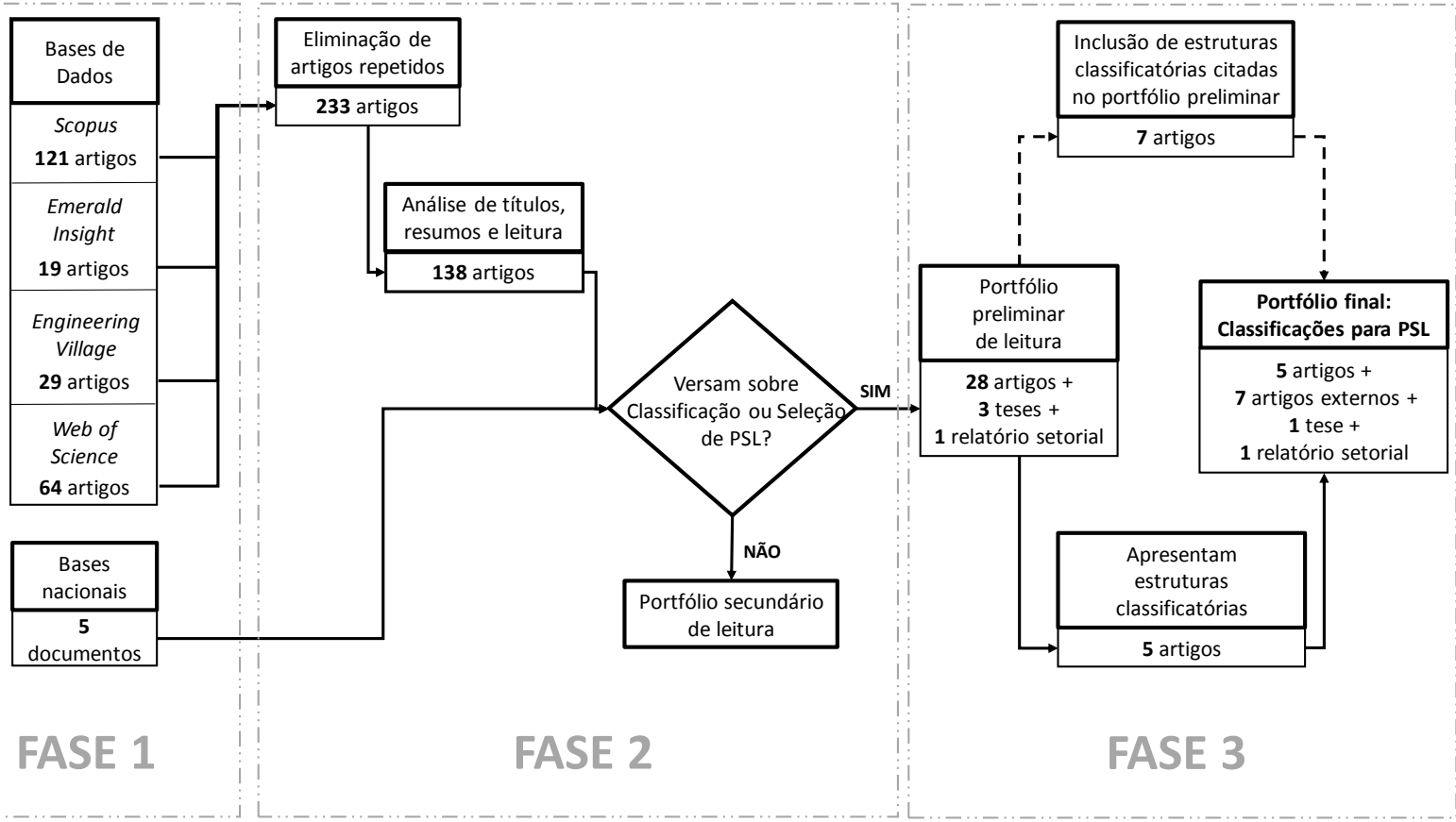

Fonte: Elaborado pelos autores, 2017.

Estes 28 artigos foram, então, lidos para identificar aqueles que propunham classificações para os PSL ou descreviam classificações de outros autores. Os que não apresentavam estruturas classificatórias apoiaram a fundamentação teórica e passaram a compor um portfólio secundário, dentre esses artigos citam-se: revisões da literatura (Aguezzoul, 2014; Alkhatib et al., 2015; Busse e Wallenburg, 2011; Marasco, 2008; Selviaridis e Spring, 2007), artigos com descrição de métodos de escolha e/ou avaliação e desempenho de PSL (Banomyong e Supatn, 2011; Multaharju e Hallikas, 2015; Hamdan e Jamie Rogers, 2008; Kavčič, Gošnik, Beker, e Suklan, 2015; Routroy, 2009) bem como propostas de avaliação de PSL muito específicas, como o caso do trabalho de Wen, Tsai, e Lin (2011), que realiza um survey para avaliar PSL do setor aéreo de cargas. Após esta etapa, restaram 5 artigos que propunham classificações de PSL (Berglund et al., 1999; Delfmann, Albers, e Gehring, 2002; Fulconis et al., 2016; Hsiao, Kemp, van Der Vorst, e Omta, 2010; Lai, Ngai, \& Cheng, 2004). Foram ainda incluídas outras sete 
propostas de classificações identificadas a partir dos trabalhos que compõe o portfólio preliminar: i) Africk e Calkins (Delfmann, Albers, e Gehring, 2002; Detoni, 2003; Hsiao et al., 2010; Selviaridis \& Spring, 2007); ii) Sheffi (Delfmann, Albers, e Gehring, 2002; Detoni, 2003; Selviaridis \& Spring, 2007); iii) Muller (Delfmann, Albers, e Gehring, 2002); iv) Bolumole (Fabbe-Costes, Jahre, \& Roussat, 2008; Selviaridis \& Spring, 2007); v) Hertz \& Alfredsson (Mora, 2006, Juga, Pekkarinen, \& Kilpala, 2008; Hsiao, Kemp, Van Der Vorst, \& Omta, 2010; Selviaridis \& Spring, 2007); vi) Stefansson (Fabbe-Costes, Jahre, \& Roussat, 2008); vii) Núñez-Carballosa \& Guitart Tarré (Fulconis, Nollet, \& Paché, 2016). A descrição destas propostas de classificação foi feita com base nos trabalhos apresentados no Quadro 2.

Para contemplar classificações dos PSL propostas por autores nacionais, foi realizada uma busca nas bases de dados de universidades brasileiras e incluída a classificação proposta por Detoni (2003). Além desta, a classificação apresentada em relatório sobre o setor de logística no Brasil também foi considerada (Costa, Vieira, e Fleury, 2002). Ao final, foram identificadas 14 estruturas classificatórias.

Quadro 2 - Estruturas de classificação identificadas

\begin{tabular}{|c|c|}
\hline DESCRIÇÃO & AUTORES \\
\hline $\begin{array}{l}\text { Estruturas de classificação oriundas da } \\
\text { busca nas bases de dados }\end{array}$ & $\begin{array}{l}\text { Berglund, van Laarhoven, Sharman, \& Wandel (1999) } \\
\text { Delfmann, Albers, \& Gehring (2002) } \\
\text { Lai, Cheng, \& Yeung (2004) } \\
\text { Hsiao, Kemp, Van Der Vorst, \& Omta (2010) } \\
\text { Fulconis, Nollet, \& Paché (2016) }\end{array}$ \\
\hline $\begin{array}{l}\text { Estruturas de classificação citadas no } \\
\text { portfólio preliminar }\end{array}$ & $\begin{array}{l}\text { Sheffi (1990) } \\
\text { Muller (1993) } \\
\text { Africk \& Calkins (1994) } \\
\text { Bolumole (2003) } \\
\text { Hertz \& Alfredsson (2003) } \\
\text { Núñez-Carballosa \& Guitart Tarré (2011) } \\
\text { Stefansson (2006) }\end{array}$ \\
\hline $\begin{array}{l}\text { Estruturas de classificação oriundas de } \\
\text { busca em bases de dados nacionais e } \\
\text { citações de autores nacionais }\end{array}$ & $\begin{array}{l}\text { Costa, Vieira, \& Fleury (2002) } \\
\text { Detoni (2003) }\end{array}$ \\
\hline
\end{tabular}

Fonte: Elaborado pelos autores, 2017.

\section{Terceirização de serviços logísticos}

A terceirização logística é parte de uma tendência de contratação de atividades da cadeia de valor de uma empresa e promoveu o surgimento dos chamados third-party logistics ou 3PL (Núñez-Carballosa e Guitart-Tarrés, 2011). Outros termos são utilizados para designar estes 
prestadores de serviços logísticos e incluem: contract logistics, integrated logistics, outsourced logistics (Yang, 2014) ou ainda, logistic service providers (Alkhatib, Darlington, e Nguyen, 2015; Selviaridis e Spring, 2007)

A tendência de transferir atividades logísticas a terceiros, iniciada nos Estados Unidos nos anos 80, foi resultado da desregulamentação do setor de transporte de cargas naquele país e provocou, em uma escala global, o crescimento da indústria de prestação de serviços logísticos (Detoni, 2003). Essa indústria evoluiu e a transferência para terceiros de um número maior de atividades, cada vez mais complexas, provocou mudanças nas organizações que contratam e que oferecem serviços logísticos. Saw (2012) observou uma tendência de crescimento no número total de funções oferecidas pelas 100 melhores PSL nos Estados Unidos, com destaque para o período entre 1998 e 2001, para qual se registrou crescimento de aproximadamente 25\% ao ano (Luna, 2001). No Brasil, o desenvolvimento do setor de logística teve início com a abertura econômica, a partir do início dos anos 1990, intensificando-se com a entrada de PSL com know-how na prestação de serviços logísticos mais complexos, e de sociedades industriais e comerciais estrangeiras mais exigentes em relação às demandas de serviços logísticos (Detoni, 2003).

O surgimento e as mudanças nessa indústria foram descritas no trabalho de Papadopoulou e Macbeth (1998), os quais, apoiados em uma abordagem baseada em contratos, identificaram cinco fases da indústria de PSL: i) fase de introdução, entre os anos 1900 a 1950, quando as empresas consideram a terceirização somente se há significativas vantagens de custos; ii) fase de conhecimento, quando os PSL ganham popularidade e as empresas começam a considerar a possibilidade de terceirizar atividades logísticas, embora ainda com a preocupação em perder o poder e o controle da sua logística; iii) fase de necessidade da terceirização pelas empresas, dos anos 1960 a 1970, quando mudanças legais e de mercado nas demandas dos serviços de distribuição levam ao aumento da complexidade das atividades logísticas; iv) fase de integração, quando o conceito dos PSL passa a interessar a um número cada vez maior de empresas, entre o final dos anos 70 até final dos anos 80; e v) fase de diferenciação, entre o fim de 1980 até final de 1990. Os autores Papadopoulou e Macbeth (1998) destacam que esta última fase é caracterizada pela oferta de serviços complexos combinados.

A oferta de serviços logísticos de maior complexidade é acompanhada pela ampliação da atuação dos PSL, que passam a desempenhar funções no âmbito da cadeia de suprimentos, muitas vezes gerenciando os fluxos logísticos entre seus vários integrantes. Como afirmam 
Fulconis, Nollet, e Paché (2016), esse papel de integrador é bem representado pelo 4PL (fourth party logistics), empresa que projeta e oferece soluções logísticas personalizadas combinando recursos dos clientes, de empresas de armazenagens, fornecedores industriais e transportadores, etc.

O crescimento no número de 4PL, ou quarteirizadores logísticos, e as vantagens associadas a esse novo modelo são destacadas nos trabalhos mais recentes, assim como as dificuldades relacionadas ao engajamento dessas várias organizações - dado que esse modelo pressupõe um comportamento colaborativo e compartilhamento de informações entre os membros da cadeia (Subramanian, Gunasekaran, Papadopoulos, e Nie, 2016). Esse aspecto foi destacado por Bronzo (2004), em trabalho nacional. Para o autor, a integração efetiva dos processos logísticos entre fornecedores e clientes da cadeia tem gerado um aumento da "densidade" do vínculo de relacionamento entre esses agentes. Esse relacionamento PSL-cliente passa a ser tratado em estudos mais recentes, que classificam as relações entre as partes ou analisam o efeito de normas contratuais e relacionais na governança das relações entre PSL, clientes e demais membros da cadeia (Selviaridis, 2016).

Para (Hosie, Sundarakani, Tan, e Koźlak, 2012), a integração dos processos logísticos é expressa pelo modelo de terceirização 5PL (fiffht party logistics), considerado uma progressão lógica dos modelos 3PL e 4PL. Segundo os autores, não há consenso sobre o que 5PL significa, existindo na literatura diversas atividades atribuídas a esse modelo, que pode incluir: coordenação eletrônica (virtual) da cadeia de suprimentos, gerenciamento de questões de cunho estratégico, atuação exclusiva no e-commerce e/ou possuem seus principais recursos na propriedade de informações.

\section{Estruturas de classificação dos prestadores de serviços logísticos}

A partir do portfólio de trabalhos selecionados, mais especificamente das 14 estruturas de classificação de PSL, procedeu-se uma etapa de análise destas classificações. Estas foram publicadas entre os anos de 1990 a 2016 e são descritas, nas seções seguintes, em ordem cronológica. Uma primeira análise permitiu identificar dois tipos de esquemas classificatórios com características distintas: as tipologias e taxonomias 
As tipologias são estruturas utilizadas para descrever classificações de dados baseados em teorias (Rich, 1992). Em geral, as tipologias são produtos de pesquisa dedutiva na qual poucas características são consideradas, sendo, muitas vezes, arbitrárias ou muito específicas. Hambrick (1984, como citado em Lambert, 2006) ressalta que as tipologias representam uma tentativa do teórico de compreender observações não quantificáveis e sendo, em grande parte, resultado de sua visão. Assim, as tipologias não refletem adequadamente a realidade e são classificações específicas, servindo a propósitos limitados. Portanto, é plausível que, ao longo do tempo, um grande número de tipologias sejam desenvolvidas, cada uma capaz de atender um objetivo específico (Lambert, 2006).

As taxonomias são estruturas de classificação derivadas de estudos empíricos, sendo consideradas como naturais e capazes de proporcionar base para generalizações (Lambert, 2006). Esse tipo de classificação é comumente utilizado para categorizar informações e conhecimentos, sendo útil para apresentar relações entre objetos e, ao mesmo tempo, facilitar a identificação de semelhanças entre eles (Rajesh, Pugazhendhi, \& Ganesh, 2011). "Uma taxonomia é empírica antes que conceitual e tem como objetivo classificar objetos em função de medidas de similaridades, segundo variáveis observáveis" Bailey (1994, como citado em Lambert, 2006).

\section{Tipologias}

No que diz respeito às classificações de PSL identificadas na literatura como tipologias, podese apontar os seguintes trabalhos: Sheffi (1990 apud Maia, 2009), Muller (1993 apud Razzaque \& Sheng 1998), Africk e Calkins (1994 apud Detoni, 2003; Lima, 2004; Maia, 2009; Razzaque \& Sheng, 1998; Delfmann et al., 2002; Fulconis et al., 2016).

Sheffi (1990 apud Maia, 2009) apresenta uma das primeiras classificações de PSL, identificando dois grandes grupos: (i) os que possuem ativos e (ii) os que não os possuem ativos. De acordo com Sheffi (1990 apud Maia, 2009), os PSL do primeiro grupo investem em ativos para seu uso próprio e vendem o excesso no mercado, aumentando paulatinamente sua capacidade e oferta de ativos. Os PSL que não possuem ativos, por sua vez, concentram suas competências no know-how, oferecendo serviços baseados nos seus recursos humanos e desenvolvimento de sistemas. 
A primeira proposta de Muller (1993 apud Razzaque \& Sheng 1998) diferencia os PSL em dois tipos: aqueles baseados em operações e os baseados em informações. Razzaque \& Sheng (1998) afirmam que, algum tempo depois, esta classificação foi alterada por Muller, que sugeriu quatro tipos de PSL, com base nos recursos que estes dispõem:

- os baseados em ativos, que oferecem serviços logísticos físicos, essencialmente usando ativos próprios, como veículos e/ou armazéns;

- os baseados em gestão, os quais não detêm ativos e estão envolvidos com a oferta de serviços de gestão logística por meio de sistema de banco de dados ou consultoria, frequentemente atuando no setor de transportes;

- os integrados, que, em geral, se baseiam em ativos, veículos e/ou armazéns, mas não se limitam ao uso de ativos próprios, subcontratando outros prestadores de serviços na medida em que for necessário; e

- os baseados em administração, que oferecem principalmente serviços de gestão administrativa como, por exemplo, pagamento de fretes.

Razzaque e Sheng (1998) afirmam que este esquema é similar ao proposto por Africk e Calkins em 1994, endossando a ideia de dois tipos principais de PSL: os baseados em ativos e os não baseados em ativos. O trabalho de Africk e Calkins inclui ainda um tipo híbrido (Lima, 2004; Maia, 2009; Razzaque e Sheng, 1998), que se caracteriza por oferecer tanto serviços de administração, ou não baseados em ativos, como serviços baseados em ativos. A tipologia proposta por Africk e Calkins (1994 apud Razzaque \& Sheng 1998) está representada no esquema da Figura 2.

Pode-se observar que, embora os autores definam três grupos de PSL em função dos tipos de serviços oferecidos, eles consideram também uma variação no grau de complexidade e personalização desses grupos, representada em um cada dos eixos. 
Figura 2 - Classificação proposta por Africk e Calkins

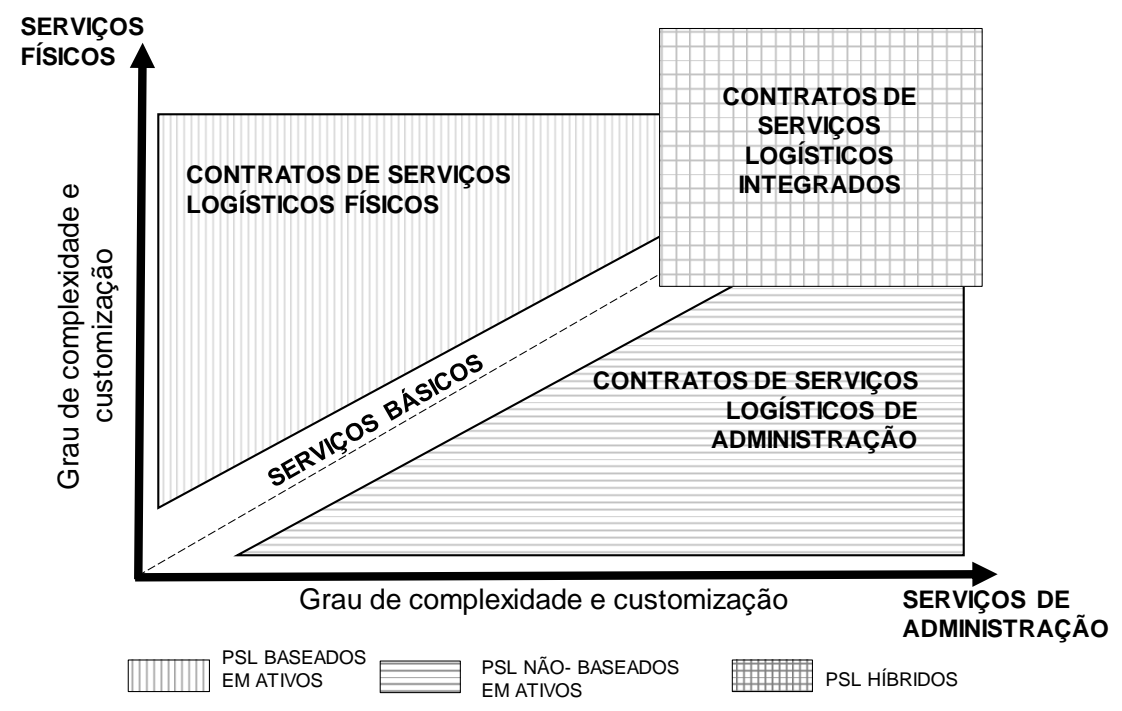

Fonte: Adaptada de Africk e Calkins (1994 apud 2004; Maia, 2009; Razzaque \& Sheng, 1998).

Uma década depois, Delfmann et al. (2002) verificaram que as tipologias para classificar os PSL identificadas na literatura, tais como as propostas por Muller (1993 apud Razzaque e Sheng 1998) e Africk e Calkins, não pareciam adequadas a contexto caracterizado pelas mudanças decorrentes do crescimento do e-commerce. Assim, os autores propõem uma nova tipologia baseada no tipo de serviço oferecido e no grau de customização, como ilustra a Figura 3, e identificam três tipos de PSL (Delfmann et al., 2002):

- os básicos, ou standardizing LSP, empresas altamente especializadas em seu campo de atuação que oferecem apenas serviços logísticos básicos e padronizados, como transporte e armazenagem, não realizando atividades de administração ou coordenação destes serviços;

- os agregadores, ou bundling LSP, que oferecem serviços logísticos básicos, como transporte, combinado com serviços secundários, como controle de qualidade e montagem de produtos - embora não customizados - sendo esse conjunto de serviços coordenados pelos PSL em uma configuração definida pela empresa cliente;

- os customizadores, ou customizing LSP, empresas que têm, como competência central, a oferta de atividades administrativas e a coordenação de serviços, inclusive prestados por outros PSL, que são contratados para atender as demandas de seus clientes. 
De acordo com Delfmann et al. (2002), os PSL customizadores projetam e desenvolvem serviços e sistemas logísticos e, além de combinar, modificam componentes de serviços de logística para atender necessidades específicas dos clientes, inclusive oferecendo serviços como finanças e atividades produtivas.

Figura 3 - Classificação de Delfmann, Albers e Gehrin.

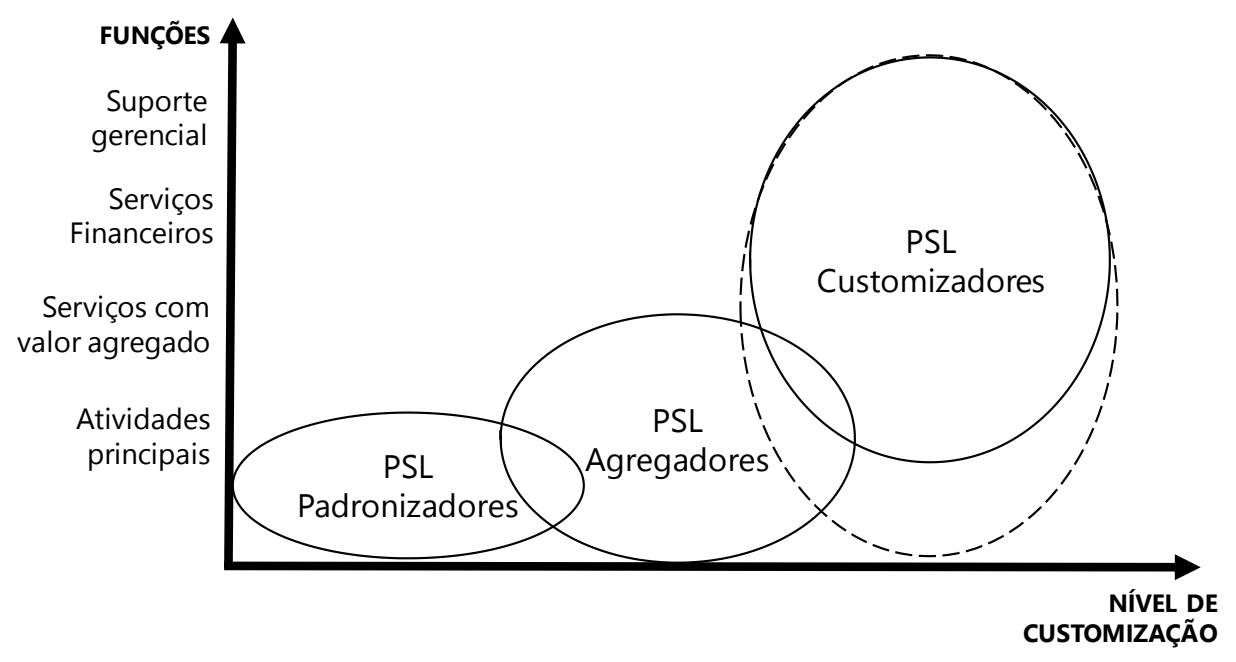

Fonte: Adaptada de Delfmann et al., (2002).

Mais recentemente, os autores Fulconis et al., (2016) propuseram uma classificação baseada na evolução dos PSL, os quais passaram de "transportadores melhorados" para "desenvolvedores de soluções logísticas completas" em cerca de 15 anos. Segundo estes autores, os PSL podem ser classificados como: i) transportadores tradicionais; ii) empresas que oferecem serviços de transporte e armazenagem, como gestão de estoque e processamento de pedidos etc; iii) empresas que oferecem outros serviços aos clientes, além do transporte e armazenagem, como apoio pós-venda e emissão de notas etc; e iv) empresas que oferecem um pacote completo de soluções, incluindo, além do transporte e armazenagem, serviços de alto valor agregado, como configuração de instalações logísticas, co-manufatura, embalagem e tecnologia da informação, tornando possível a venda de serviços modulares e customizados. Os círculos concêntricos, apresentados na Figura 4, além de representarem essas categorias de PSL, destacam a evolução da indústria logística, inicialmente caracterizada pela oferta de serviços com base nas competências centrais dos PSL, como transporte e armazenagem (Círculos 1 e 2), e que posteriormente foi se expandindo e passando a incluir serviços de maior 
valor agregado (Círculo 3 e 4). Os autores citam que a proposta apresentada está baseada nos trabalhos de Fulconis, Paché, e Roveillo (2011) e Michon (2014).

Figura 4 - Classificação de Fulconis, Nollet, e Paché

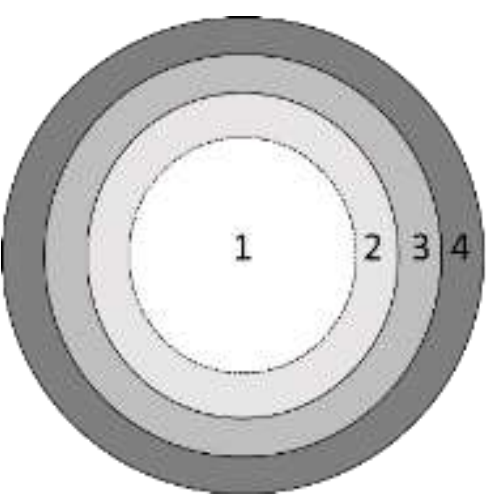

Fonte: Adaptada de Fulconis et al., (2016).

\section{Taxonomias}

Em relação às classificações de PSL caracterizadas como taxonomias, foram identificadas nove propostas. O trabalho de Berglund et al. (1999) foi um dos primeiros apresentados na literatura. Por meio de um survey conduzido no final da década de 1990 com 21 empresas PSL consideradas inovadoras ou de destaque no setor, Berglund et al. (1999) identificaram diferenças significativas nas estratégias adotadas pelos PSL. A proposta dos autores foi embasada nas respostas completas fornecidas por dez empresas localizadas na Europa, oito nos Estados Unidos e uma na Austrália. Os autores Berglund et al. (1999) identificaram duas principais dimensões que diferenciavam os PSL: o tipo de serviço oferecido e o valor agregado dos serviços. Em relação ao tipo de serviço, os PSL podem oferecer um serviço específico como, por exemplo, distribuição de peças de reposição, ou uma gama mais ampla de serviços, ou seja, uma solução completa ao cliente.

Essas duas categorias são identificadas, na Figura 5, como serviço ou solução. Considerando a segunda dimensão, Berglund et al. (1999) diferenciam os PSL em função dos serviços que realizam, ou seja, somente serviços tradicionais, como transporte e armazenagem, ou outros serviços com maior valor agregado. 
Figura 5 - Classificação de Berglund, van Laarhoven, Sharman, e Wandel

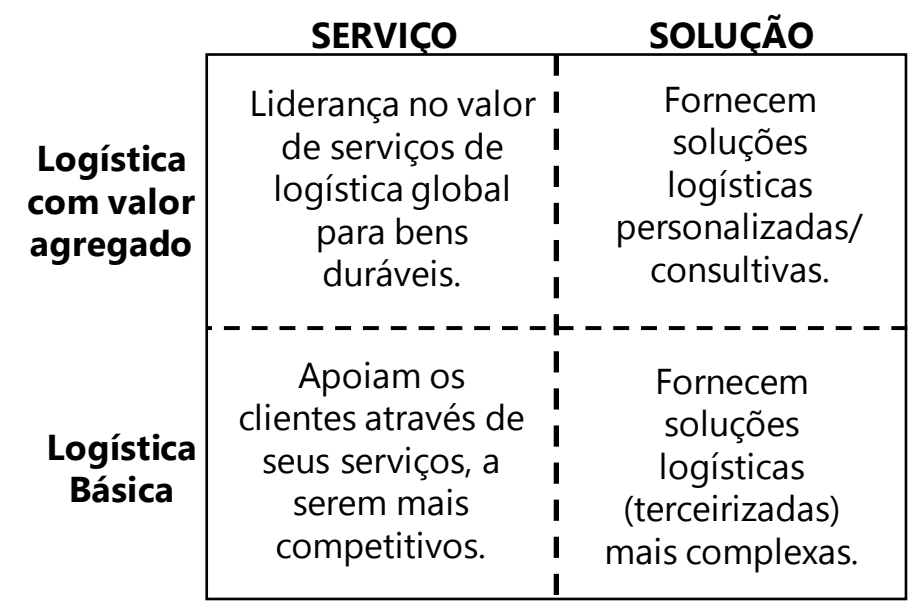

Exemplos

Processamento

de pedidos,

Montagem de

kits, Projeto de redes de distribuição

Transporte,

Armazenagem,

Consolidação/

Desconsolidação,

Etiquetagem.

Fonte: Adaptada de Berglund et al., (1999).

Uma segunda taxonomia identificada foi proposta por Costa et al. (2002), a qual está embasada em dados do mercado brasileiro de serviços logísticos. A pesquisa conduzida por Costa et al. (2002) é patrocinada por uma empresa de consultoria e incluiu duas etapas: aplicação de questionário, que obteve taxa de reposta de 50\%, equivalente a 67 empresas, seguido de entrevistas em profundidade com alguns dos PSL de maior destaque no Brasil e clientes desses PSL que atuam em diferentes setores: alimentício, automotivo, de bebidas e farmacêutico.

De acordo com os resultados apresentados, os PSL se diferenciam segundo três dimensões principais: i) cobertura geográfica; ii) sofisticação da oferta de serviços; e iii) complexidade logística da indústria servida, que depende do número de SKUs (stock keeping units), do valor dos itens/peso, do tamanho dos embarques e requisitos especiais para armazenagem e manuseio dos itens (Costa et al., 2002). Com base nestes critérios foram identificados seis clusters ou classes de empresas PSL:

- nacionais de serviços básicos, que oferecem serviços de transporte e/ou armazenagem, iniciando suas atividades em uma região com um serviço básico e se expandindo nacionalmente;

- regionais de serviços básicos, que procuram se destacar pela excelência operacional de serviços de transporte e/ou armazenagem, servindo indústrias de diferentes graus de complexidade logística, mas concentradas regionalmente;

- integradores nacionais incipientes, que oferecem alguns serviços de maior valor agregado, além do transporte e armazenagem, e têm o objetivo de se tornarem 
provedores de serviços logísticos integrados, atendendo indústrias de diferentes níveis de complexidade e oferecendo uma mais ampla cobertura geográfica, como o Mercosul;

- integradores regionais incipientes, que buscam oferecer serviços de mais alto valor agregado, atuando na região Sudeste e mais alguma outra região do país e prestando serviços para indústria de média complexidade, diferenciando-se dos integradores nacionais por atenderem uma maior base de clientes;

- serviço expresso, que são empresas aéreas ou de courier, com cobertura nacional, e que oferecem serviços de mais alto valor agregado com forte ênfase em tecnologia de informação e confiabilidade de serviços;

- integradores em evolução orientados aos clientes, que pretendem oferecer solução completa - one-stop - aos seus clientes e são, em grande maioria, apoiadas ou pertencentes a grandes players internacionais e concentrando suas operações, principalmente, nas regiões e sul e sudeste.

Na Figura 6, tem-se a representação pictográfica da taxonomia proposta, com a identificação das seis classes de PSL numeradas de 1 a 6, identificando, respectivamente, as empresas: nacionais de serviços básicos, regionais de serviços básicos, integradores nacionais incipientes, integradores regionais incipientes de serviço expresso e integradores em evolução orientados aos clientes.

Figura 6 - Classificação de Costa, Vieira e Fleury

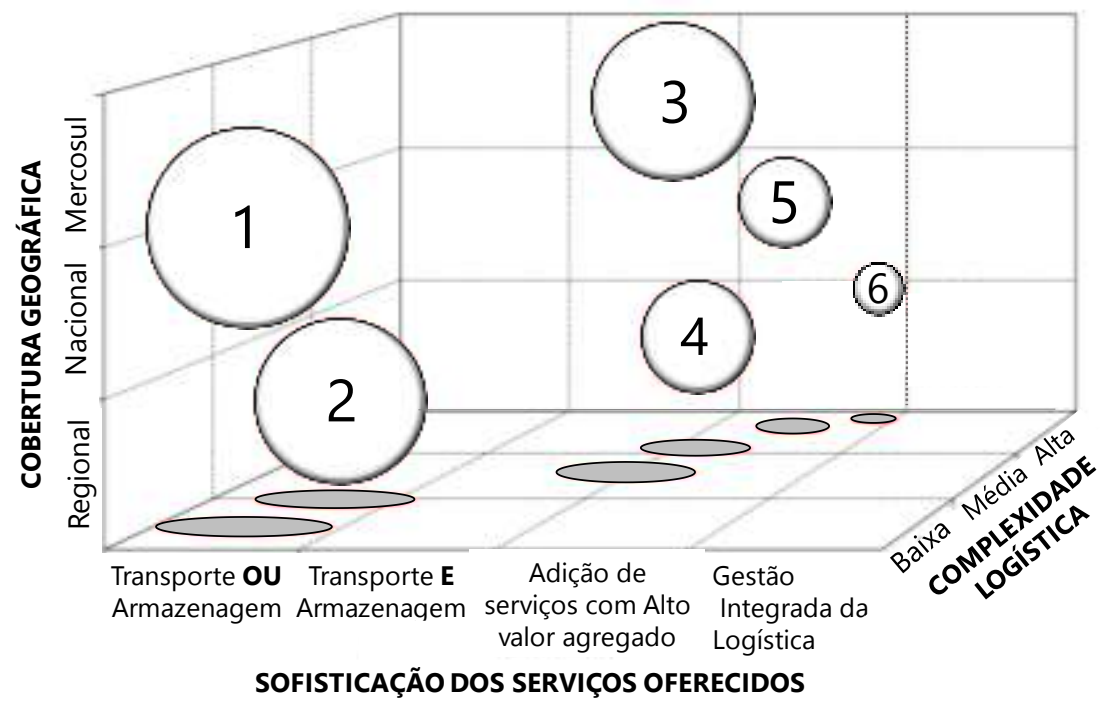

Fonte: Adaptada de Costa et al. (2002). 
Vale ressaltar que, ainda de acordo com Costa et al. (2002), estas seis classes podem ser agrupadas em duas principais: i) as empresas que buscam excelência operacional em uma gama limitada de serviços, a qual é representada pela maior parte da amostra e engloba as classes 1 e 2; e ii) as empresas que estão ampliando os serviços oferecidos para incluir o projeto, a implementação e operação de soluções integradas, e inclui as classes 3, 4, 5 e 6.

Também usando dados do mercado brasileiro de PSL, Detoni (2003) apresenta uma taxonomia desenvolvida a partir de análise estatística multivariada de uma amostra de 107 empresas caracterizadas por 58 variáveis. A autora classificou os PSL segundo uma estrutura baseada em três fatores, identificados com auxílio de Análise de Componentes, quais sejam: (i) fator arco, caracterizado pela oferta de serviços baseados em gestão de transações e informações, menos concentrados em uma facilidade logística, a exemplo do serviços de transportes; (ii) fator propriedade de ativos, que engloba variáveis relacionadas a propriedade de ativos, como frota própria, número de armazéns e de equipamentos de movimentação; (iii) fator nó, relacionado com variáveis que indicam a oferta de serviços de mais alto valor, como serviços de armazenagem, número de funcionários e equipamentos de movimentação mecânica, e concentração da oferta de serviços para poucos clientes. As empresas PSL são, assim, classificadas em 8 grupos. Detoni (2003) ainda identifica, por meio de análise de clusters, quais empresas, dentre as 105 empresas consideradas em sua amostra, pertencem a cada octante. A classificação proposta por Detoni é representada graficamente na Figura 7.

Figura 7 - Classificação de Detoni

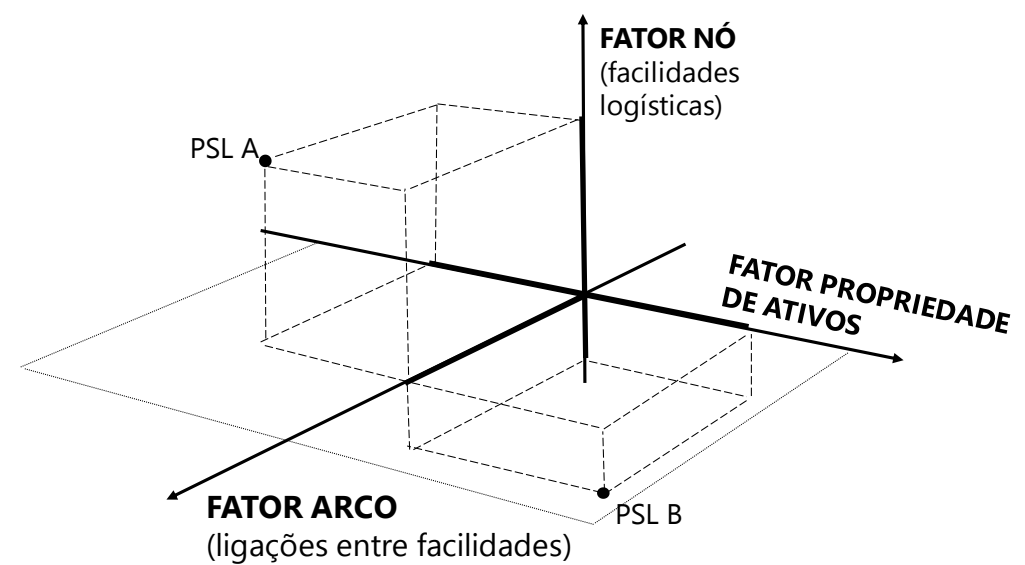

Fonte: Adaptado de Luna (2015). 
Bolumole (2003) apresenta uma taxonomia desenvolvida a partir de trabalho anterior do mesmo autor (Bolumole, 2001), no qual descreve três estudos de caso no setor de distribuição de petróleo no Reino Unido. O autor identificou, a partir desses estudos, quatro fatores que influenciam o papel dos PSL na cadeia de suprimentos: i) orientação estratégica da organização; ii) percepção do papel do PSL na estratégia logística; iii) natureza da relação cliente-PSL; e iv) extensão da terceirização logística. A combinação destes fatores permitiu ao autor propor uma estrutura para identificar PSL com diferentes funções, as quais são descritas em Bolumole (2003):

- funções operacionais com foco interno, mantendo uma relação com seus clientes baseada em transações, nas quais o principal objetivo dos clientes é a redução de custos, buscando a terceirização de serviços como transporte e armazenagem, com pouco valor agregado;

- funções operacionais com foco externo, onde o PSL reconhece a importância das suas operações para a cadeia de suprimentos e oferece ao cliente uma vantagem competitiva a partir das suas competências essenciais, apesar de uma relação ainda baseada em transações;

- funções táticas com foco interno em uma relação mais próxima com o cliente, caracterizada pelo maior envolvimento do PSL nas operações in-house onde o PSL passa a ser visto como o "departamento de logística interna da empresa";

- funções táticas com foco externo em uma relação mútua baseada nas competências do PSL, nos quais os PSL proveem serviços ou capacidades logísticas adicionais, como instalações em períodos de picos de demanda que permitam aos seus clientes atingir metas de serviços no curto ou médio prazo;

- funções estratégicas com foco interno em uma relação de parceria com o cliente, na qual os PSL buscam se organizar e desenvolver recursos, com foco nos custos, que os permitam alcançar os objetivos estratégicos internos definidos pelos clientes, sem uma preocupação com uma integração com a cadeia de suprimentos - este tipo de relação entre cliente e PSL pode levar ao desenvolvimento de joint ventures;

- funções estratégicas com foco externo, onde os PSL agem para facilitar a coordenação das funções logísticas ao longo da cadeia, gerenciando o fluxo de informações para 
integrar a empresa à sua rede logística e assumindo responsabilidades que agregam valor aos parceiros.

A estrutura sugerida por Bolumole (2003) está representada na Figura 8, mas destaca o autor que esta não é generalizável, tendo em vista a complexidade das operações na cadeia de suprimentos. Além disso, segundo Bolumole (2003), a estrutura sugerida pode ser usada para avaliar esta dinâmica dos PSL que, ao longo do tempo, têm mudado de uma oferta de serviços mais básicos e isolados para serviços mais completos considerando o contexto da cadeia de suprimentos, ou seja, se movimentando entre as classes identificadas pelo autor.

Figura 8 - Classificação de Bolumole

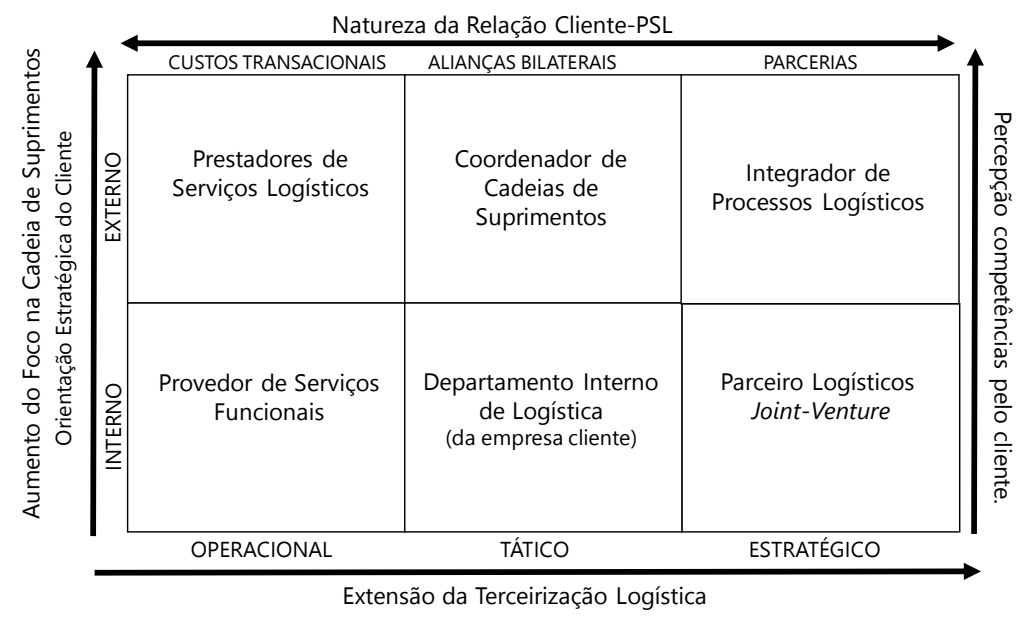

Fonte: Adaptada de Bolumole (2003)

Em 2003, Hertz e Alfredsson (2003) trataram das mudanças dos PSL em uma indústria em crescimento e das suas relações com clientes e parceiros para atender novas demandas. Com este objetivo, realizaram estudos de casos com quatro PSL - ASG, Transfargo, CatLogistics e DHL - seus clientes e os clientes de seus clientes. Segundo os autores, os PSL, em geral tem buscado desenvolver habilidades, competências e obter vantagens relacionadas à escala e escopo para agregar valor aos seus clientes. Com base nos estudos de casos e em revisão da literatura, os autores identificaram duas dimensões para classificar as empresas PSL: i) as demandas relacionadas à coordenação dos clientes; e ii) a habilidade de se adaptar e solucionar problemas (Hertz e Alfredsson, 2003). Quatro subgrupos de PSL são então identificados, os quais estão representados na Figura 9: 
- o tradicional, que pode ser visto como o provedor de serviços padronizados, oferecendo serviços como transporte e armazenagem;

- o desenvolvedor de serviços, que oferece serviços diferenciados, e com maior valor agregado, para diferentes clientes, ou pacotes de serviços que frequentemente envolvem vários grupos de atividades padronizadas moduladas, cujos módulos são combinados em função das demandas de cada cliente;

- o transformador do cliente, que é descrito como o PSL que assume as atividades dos clientes buscando melhorar sua eficiência, podendo, por exemplo, responsabilizar-se pelos armazéns dos clientes e a execução de suas atividades logísticas;

- o desenvolvedor de clientes, ou integrador logístico, que constitui o tipo mais avançado e complexo, por assumir todas as operações logísticas dos clientes; este tipo de PSL equivale ao chamado 4PL ou quarteirizador.

Figura 9 - Classificação de Hertz e Alfredsson

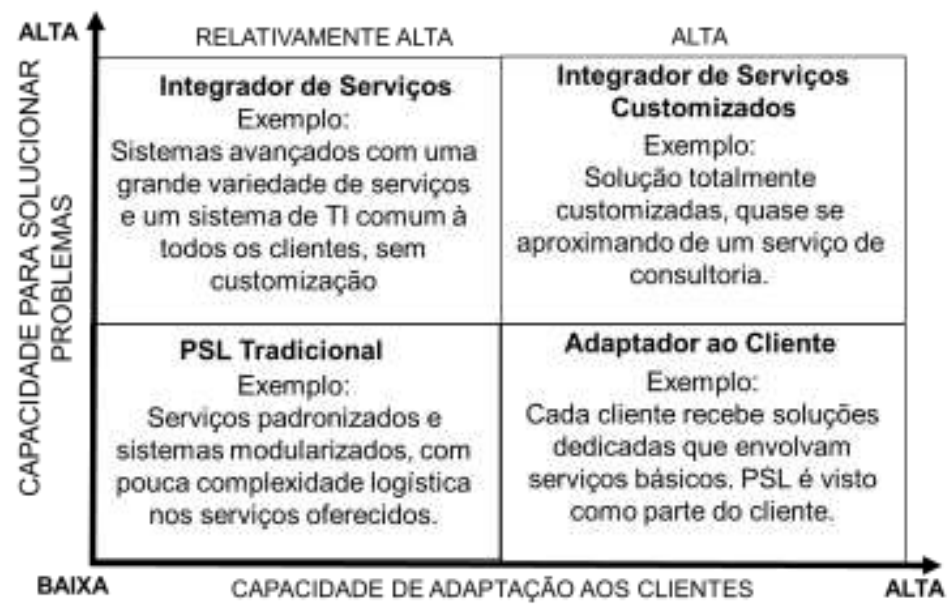

Fonte: Adaptada de Hertz e Alfredsson (2003).

Embora os autores Hertz e Alfredsson (2003) não incluam, de forma explícita na estrutura de classificação, critérios que tratem do relacionamento PSL-cliente, eles destacam, ao longo do trabalho, que à medida que os serviços oferecidos pelos PSL se tornam mais complexos, passam a ter implicações sobre o relacionamento do PSL com seus clientes, pois exigem a coordenação das atividades de seus clientes e dos fornecedores, e clientes de seus clientes.

Embasada em resultados de um survey com 221 empresas, membros da Associação de Agenciadores de Carga e Logística de Hong Kong (Association of Freight Forwarding and 
Logistics Limited, HAFFA) ou listadas na Revista de Transportes Marítimos de Hong Kong, Lai, Ngai, e Cheng (2004) usaram ferramentas de estatística multivariada - análise fatorial, análise de variância e análise de clusters - para propor uma segmentação dos PSL. Como resultado da análise de fatorial, a autora identificou três fatores: i) serviços logísticos de valor agregado que engloba elementos tais como montagem, embalagem, processamento de pedidos, gestão de frotas armazenagem; ii) serviços logísticos baseados em tecnologia, concernente a variáveis relacionadas a rastreamento de cargas, expedição e recebimento de cargas e Electronic data interchange (EDI); e iii) agenciamento de cargas ou serviços de despachantes. Em seguida, com base na análise da variância e análise de clusters, identificou quatro categorias de PSL e as nominou como (Lai, 2004):

- agenciadores de carga, ou traditional freight forwarders, com baixíssima competência para oferecer serviços de mais alto valor agregado e/ou serviços baseados em tecnologia;

- transformadores, ou transformers, que se diferenciam pela sua competência de oferecer serviços de valor agregado e serviços baseados em tecnologia, o que sugere que sejam PSL em transição, esforçando-se para transformarem em provedores completos;

- operadores logísticos, ou full service providers, com mais alto desempenho de todos os quatro clusters e, segundo os três fatores, são considerados os líderes de mercado;

- operadores de nichos, ou nichers, possuem baixa competência para oferecer serviços de carga, mas média competência em serviços de valor agregado e de tecnologia, parecendo indicar que atuam em nichos de mercado, seja oferecendo serviços como armazenagem e processamento de pedidos, ou de gestão de informação.

Stefansson (2006) propõe uma taxonomia para os PSL com base em resultados de trabalhos anteriores, dentre os quais se inclui Stefansson (2004), e estudos de múltiplos casos. Os dados usados para propor a taxonomia foram obtidos por meio de entrevistas aos seguintes PSLs: Schenker International sobre os serviços para Dell Computers na Irlanda e Grundfos na Dinamarca; Celexor sobre serviços para IKEA na Suécia, e a DSC Logistics, nos Estados Unidos, sobre os serviços logísticos para a Kimberly-Clark. 
Para Stefansson (2006), o papel dos PSL varia em função do grau de terceirização, o qual varia de serviços de transporte a serviços integrados de valor agregado. Assim, os PSL podem ser identificados três grupos:

- transportadores, empresas que oferecem transporte porta-a-porta, distribuição ou transporte de insumos, e também oferece serviços, como administração de transporte, documentação, rastreamento de cargas ou avaliação de desempenho;

- prestadores de serviços logísticos, que fornecem diversos serviços além do transporte, tais como cross-docking, consolidação e desconsolidação de cargas, processamento de pedidos, emabalagem e reembalagem, retorno de produtos, rastreamento de cargas, previsão e gestão de estoques, desembaraço aduaneiro, pagamentos etc;

- intermediários logísticos, ou logistics service intermediaries, que não lidam diretamente (nem fisicamente) com os bens, mas administram as diferentes atividades logísticas, além de projetar, implementar e operar instalações logísticas, selecionar e contratar PSL, oferecendo serviços altamente customizados e baseados em gestão da informação.

Figura 10 - Classificação de Stefanssson

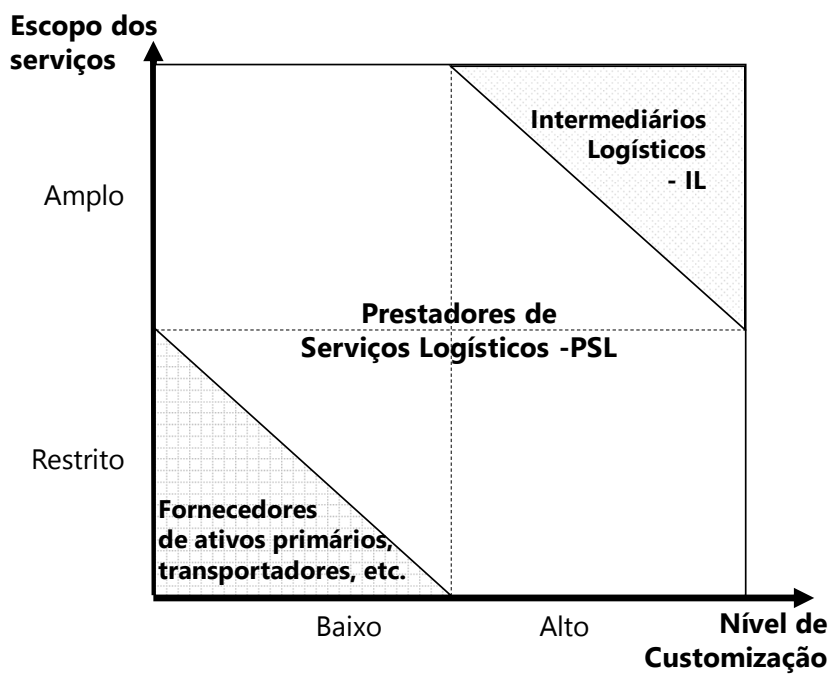

Fonte: Adaptada de Stefansson (2006).

Diferentemente das classificações apresentadas anteriormente, Hsiao et al. (2010) analisam se a terceirização de diferentes atividades logísticas leva a diferenças no desempenho de serviços logísticos e, com esse objetivo, propõem uma classificação de conjuntos daquelas 
atividades. Os autores se baseiam na distinção tradicional entre as atividades básicas e as de planejamento e controle, e sugerem quatro níveis: i) o nível 1 inclui atividades como transporte e armazenagem, sendo caracterizado por relações de curto prazo entre PSL e clientes; ii) o nível 2 inclui atividades com valor-agregado, referindo-se a atividades normalmente desempenhadas pelos fabricantes, mas que passam a ser realizadas na distribuição como, por exemplo, parte do processamento final; iii) o nível 3, um dos que está relacionado com atividades de planejamento e controle, inclui atividades como gerenciamento de estoques e de transporte, para as quais os PSL oferecem soluções logísticas customizadas; e iv) o nível 4, relacionado às atividades de gestão da rede de distribuição, inclui decisões que dizem respeito, por exemplo, a mudanças na rede de transportes, no modo de transportes, e alteração das responsabilidades dos envolvidos na cadeia de suprimentos.

A taxonomia mais recente, dentre as identificadas na revisão de literatura, foi proposta por Núñez-Carballosa e Guitart-Tarrés (2011) com base em uma pesquisa realizada na Espanha, que incluiu tanto PSL quanto empresas clientes de diferentes setores. Estudos de casos com PSL permitiram identificar duas variáveis que as diferenciavam: os serviços oferecidos e a cobertura geográfica. A proposta dos autores considera quatro categorias para distinguir os PSL: serviços fornecidos, que podem ser genéricos ou específicos, e a cobertura geográfica, nacional ou internacional (Quadro 3).

Quadro 3 - Classificação de Núñez-Carballosa e Guitart-Tarrés

\begin{tabular}{|c|c|c|}
\hline $\begin{array}{r}\text { Serviços } \\
\text { Fornecidos }\end{array}$ & Genérico & Específico \\
\hline $\begin{array}{r}\text { Cobertura } \\
\text { Geográfica }\end{array}$ & Nacional & Internaciona \\
\hline
\end{tabular}

Fonte: Adaptado de Núñez-Carballosa e Guitart-Tarrés (2011)

\section{Análise e discussão dos resultados}

A abordagem temporal adotada neste trabalho para analisar as estruturas de classificação dos PSL permite verificar que, enquanto os artigos que propõem tipologias foram publicados principalmente no início da década de 1990, a maior parte das taxonomias são propostas a partir do início dos anos 2000. Isto parece indicar um crescente interesse em compreender a realidade do setor e a sua dinâmica, ratificado pelo maior número pesquisas conduzidas no 
período em que o setor alcança mais altas taxas de crescimento. Vale ressaltar que essas taxas giravam em torno de $25 \%$ nos Estados Unidos no início dos anos 2000, enquanto hoje alcançam cerca de $5 \%$.

A relação entre os vários trabalhos - por meio da identificação dos autores e citações nas publicações analisadas - permite observar que as taxonomias, em geral, citam as tipologias propostas anteriormente, como mostra a Figura 11. À exceção do trabalho de Bolumole (2003), todos os demais parecem se embasar nas classificações previamente sugeridas para propor uma nova classificação dos PSL. Mesmo Fulconis et al. (2016) baseiam-se na tese de Michon (2014), que traz uma revisão da literatura e faz citações indiretas dos trabalhos identificados.

Figura 11 - As tipologias e taxonomias propostas e a relação entre os trabalhos.

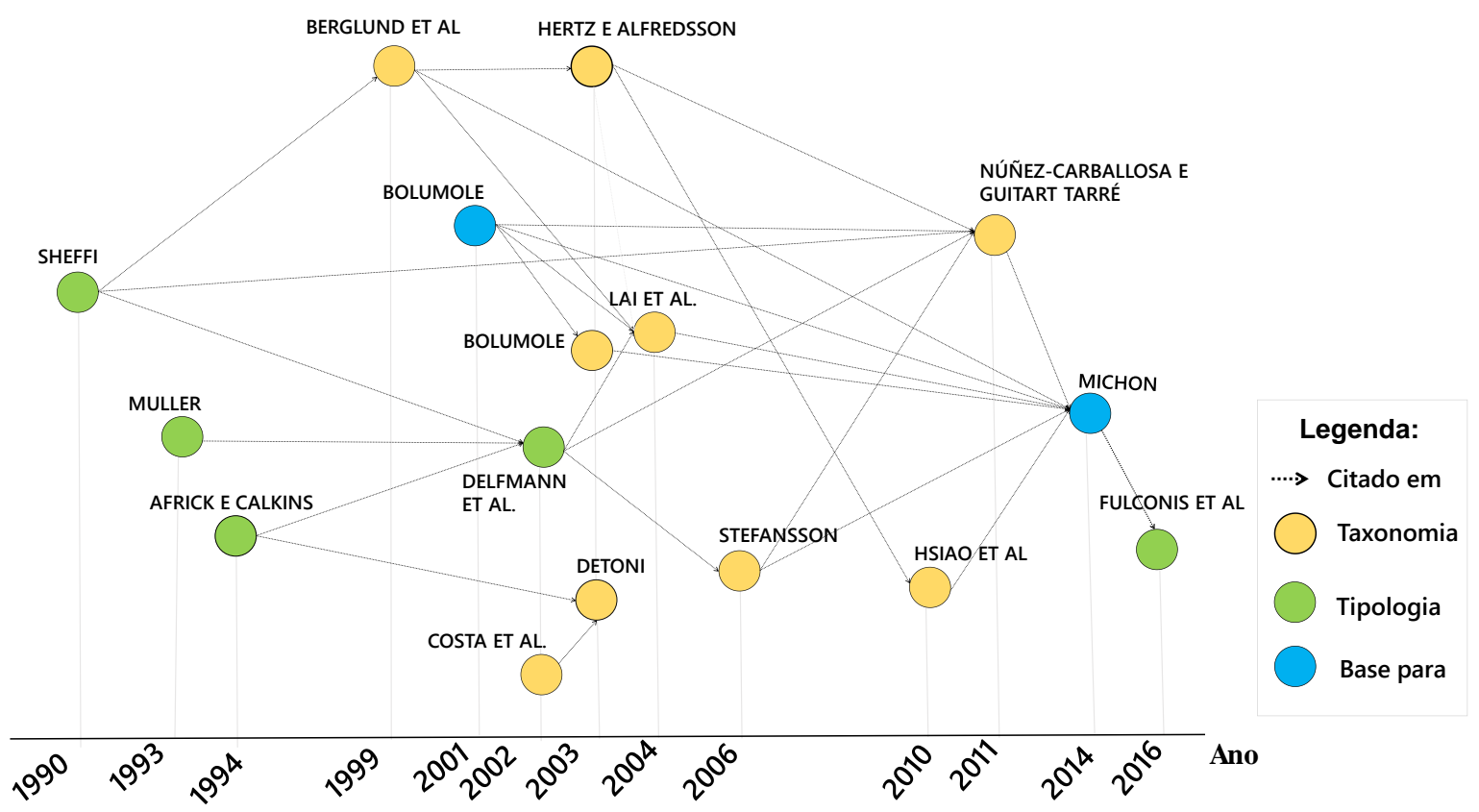

Fonte: Elaborada pelos autores, 2017.

As primeiras tipologias destacam ou estão baseadas em critérios relacionados à propriedade de ativos para diferenciar os PSL. A propriedade de ativos é vista pelos autores como determinante do tipo de serviço a ser oferecido: se básicos ou de administração. Ou seja, a propriedade de veículos e instalações define se o PSL oferece, por exemplo, serviços de transporte e armazenagem, respectivamente. A partir da tipologia proposta por Delfmann, et al. (2002), o critério "propriedade de ativos" deixa de ser considerado mas, a diferenciação dos PSL em função da oferta de "serviços baseados ou não em ativos" continua a constituir um 
critério usado para diferenciar os PSL. Esta observação sustenta a ideia que há, a partir deste período, início dos anos 2000, a desvinculação entre a propriedade de ativos e a oferta de serviços baseado em ativos, dado que PSL passam a subcontratar serviços de transporte e armazenagem para oferecer aos seus clientes a solução completa, conforme pode se observar no Quadro 5.

É nesse período que critérios como "grau de complexidade dos serviços" e "customização de serviços" passam a ser considerados nas classificações. A tipologia sugerida por Africk e Calkins é a primeira a incluir critérios relacionados à complexidade e grau de customização dos serviços oferecidos pelos PSL na sua representação esquemática, embora não apresentada claramente na descrição das três categorias que propõem. Na verdade, o grau de complexidade dos serviços ofertados, ou seja, se o PSL oferece, principalmente, serviços de transporte e/ou armazenagem ou serviços de mais alto valor agregado - como aqueles baseados em tecnologia da informação, engenharia e outros - passa a ser um critério presente na quase totalidade das estruturas de classificação propostas posteriormente, conforme se observa nos Quadros 4 e 5.

Quadro 4 - Tipologias e critérios identificados

\begin{tabular}{|c|c|c|c|c|c|}
\hline & 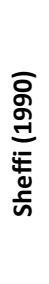 & 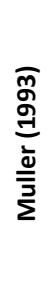 & 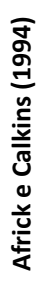 & 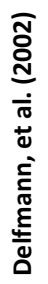 & 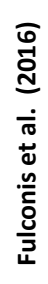 \\
\hline Propriedade de Ativos & • & $\bullet$ & $\bullet$ & & \\
\hline Serviços baseados em ativos e não-baseados em ativos & & - & • & - & \\
\hline Grau de complexidade dos serviços (básicos $X$ valor agregado) & & & • & & • \\
\hline Customização dos Serviços & & & - & - & - \\
\hline
\end{tabular}

Fonte: Elaborado pelos autores, 2017.

Na análise das taxonomias, observa-se uma variedade maior de critérios, quando comparadas às tipologias, dada a necessidade de melhor compreender a realidade da indústria usando critérios que vão além daqueles citados nas teorias. O relacionamento entre o PSL e o cliente, a atuação na rede logística e a cobertura de mercado são exemplos de critérios não considerados nas tipologias. O setor de atuação, a propriedade de ativos e a atuação na rede, por sua vez, são citados somente nas pesquisas realizadas no Brasil (Costa, Vieira, e Fleury, 
2002; Detoni, 2003) por razões relacionadas ao desenvolvimento tardio da indústria de PSL, levando ao destaque de critérios não mais usados em outros países. Na verdade, como as taxonomias são obtidas empiricamente, é natural que se identifique uma maior variedade de critérios, dado que se procura uma representação adequada das classes de PSL em diferentes contextos.

Por outro lado, classes sugeridas nas tipologias, muitas vezes, não são adequadas quando se analisam os objetos no mundo real. Apesar disso, observa-se que os critérios, grau de complexidade dos serviços e customização dos serviços estão presentes na maioria das taxonomias.

Quadro 5 - Taxonomias e critérios identificados

\begin{tabular}{|c|c|c|c|c|c|c|c|c|c|}
\hline & 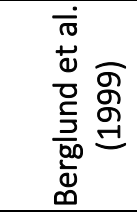 & 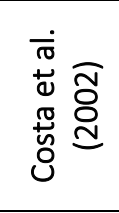 & 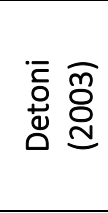 & 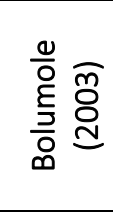 & 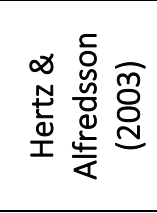 & 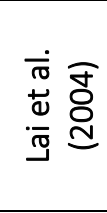 & 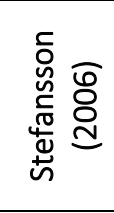 & 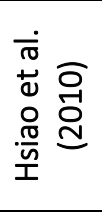 & 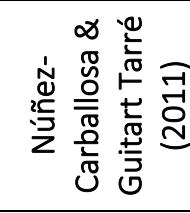 \\
\hline $\begin{array}{l}\text { Grau de } \\
\text { complexidade } \\
\text { dos serviços } \\
\text { (básicos x valor } \\
\text { agregado) }\end{array}$ & • & • & & $\bullet$ & • & • & $\bullet$ & • & • \\
\hline $\begin{array}{l}\text { Customização } \\
\text { dos serviços }\end{array}$ & • & & & • & • & & • & $\bullet$ & \\
\hline $\begin{array}{l}\text { Complexidade } \\
\text { da indústria }\end{array}$ & & $\bullet$ & & & & & & & \\
\hline $\begin{array}{l}\text { Cobertura } \\
\text { geográfica }\end{array}$ & & • & & & & & & & • \\
\hline $\begin{array}{l}\text { Escopo de } \\
\text { atuação } \\
\text { (empresa x } \\
\text { cadeia) }\end{array}$ & & & & • & & & & & \\
\hline $\begin{array}{l}\text { Relacionamento } \\
\text { com empresa- } \\
\text { cliente }\end{array}$ & & & & • & • & & & & \\
\hline $\begin{array}{l}\text { Atuação na rede } \\
\text { (arcos x nós) }\end{array}$ & & & $\bullet$ & & & & & & \\
\hline $\begin{array}{l}\text { Propriedade de } \\
\text { ativos }\end{array}$ & & & • & & & & & & \\
\hline
\end{tabular}

Fonte: Elaborado pelos autores, 2017. 
Ao mesmo tempo em que embasaram as taxonomias propostas, as estruturas de classificação sugeridas nas tipologias parecem ser ratificadas por meio das pesquisas empíricas. A inclusão de critérios, como grau de complexidade e a customização dos serviços, é reflexo tanto de mudanças na estratégia das empresas que oferecem serviços logísticos - as quais foram evoluindo de transportadores e empresas de armazenagem tradicionais, para empresas que oferecem serviços de mais alto valor agregado e caracterizados por uma maior complexidade Fulconis et al. (2016) - quanto das novas demandas dos clientes, que passaram a exigir soluções em um contexto caracterizado pela maior concorrência e exigências associadas ao nível de serviços oferecido. Assim, esta complexidade leva à necessidade de soluções personalizadas, na medida em que soluções completas passam a incluir vasta gama de atividades logísticas contratadas.

Os critérios relacionados à complexidade e customização de serviços são os que se destacam a partir dos anos 2000, os quais são considerados tanto nas primeiras tipologias quanto nas mais recentes taxonomias, como ilustra a Figura 12. Vale ressaltar também que taxonomias mais recentes incluem critérios relativos à "atuação dos PSL na cadeia logística", coerente com a tendência dos PSL assumirem o papel de integradores logísticos, e "relacionamento entre o PSL e o cliente". Este último ganha destaque a partir do momento que a colaboração e compartilhamento de informações entre o PSL, seus clientes e demais membros da cadeia passa a ser fundamental para o desempenho das funções de integrador logístico assumida recentemente pelos novos 4PL.

Figura 12 - Estruturas classificatórias e critérios identificados

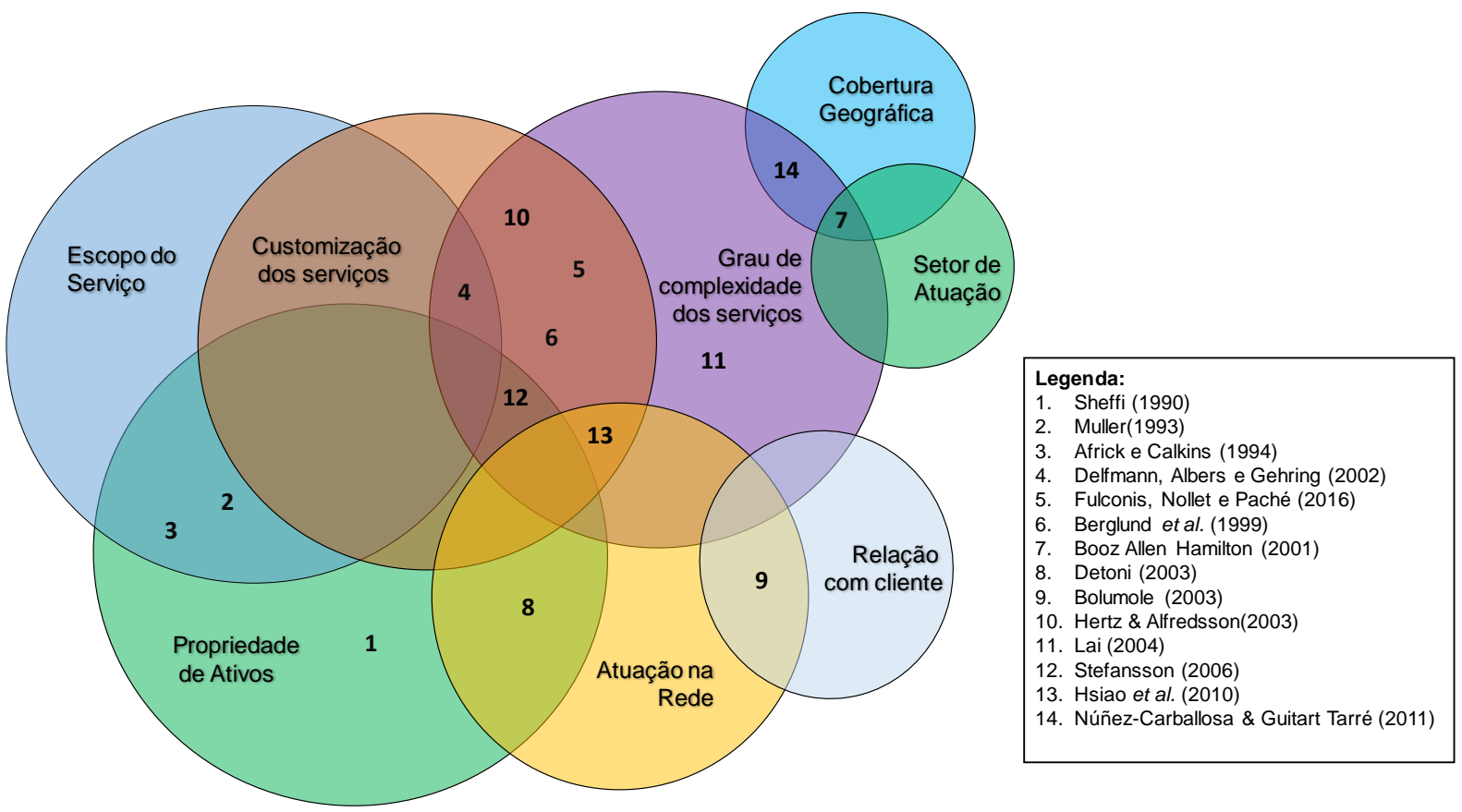

Fonte: Elaborado pelos autores, 2017. 


\section{Conclusões}

As classificações propostas para diferenciar os PSL presentes na literatura são diversas e refletem a dinâmica da indústria de PSL ao longo das últimas décadas. O presente artigo, ao identificar os critérios usados para embasar as tipologias e taxonomias, mostra uma relação entre estas estruturas de classificação e as mudanças no perfil das empresas PSL que, por sua vez, são decorrentes de novas demandas de mercado.

As primeiras tipologias propostas adotam a "propriedade de ativos" como principal critério para diferenciar os PSL, critério que vai perdendo importância ao longo do tempo. A oferta de serviços de maior complexidade, com mais alto valor agregado ou, ainda, projetados para atender às demandas dos clientes, passa a ser consideradas nas classificações subsequentes. Estudos conduzidos no Brasil sobre o mercado dos PSL no início dos anos 2000 ainda destacam os critérios "propriedade de ativos" nas taxonomias propostas, fato que pode ser justificado pela tardia abertura econômica do país e entrada, a partir deste período, de PSL com capacidade para oferecer serviços diferenciados.

Um maior número de trabalhos, em especial que propõe taxonomias, foi identificado no início dos anos 2000, período que coincide com a fase de maior crescimento da indústria de PSL nos EUA e parece refletir o maior interesse em pesquisas empíricas. A partir desta fase, os critérios usados pelos autores para classificar as empresas PSL incluem de forma reiterada, a complexidade e a personalização dos serviços logísticos. De fato, a atuação dos PSL passa a ser caracterizada pela oferta de um número cada vez maior de serviços oferecidos de forma integrada, ao invés da oferta de atividades isoladas. Em decorrência disso, o relacionamento cliente-PSL ganha importância sendo incluído em algumas taxonomias propostas. Além disso, cresce a importância dos integradores logísticos, ou 4PL, que passam a constituir objeto de mais recentes propostas de classificações.

Esta pesquisa identificou 14 estruturas classificatórias, tipologias e taxonomias, em um horizonte de publicação de 26 anos. Não foram incluídas, nesta análise, publicações que propunham classificações de 4PL ou do tipo de relações mantidas entre PSL e cliente, temas que podem constituir objeto de futuros trabalhos. 


\section{Referências}

Aguezzoul, A. (2014). Third-party logistics selection problem: A literature review on criteria and methods. Omega, 49, 69-78. https://doi.org/10.1016/j.omega.2014.05.009

Alkhatib, S. F., Darlington, R., Nguyen, T. T., \& Saleh Fahed Alkhatib , Robert Darlington, T. T. N. (2015). Logistics service providers (LSPs) evaluation and selection literature review and framework development. Strategic Outsourcing, 8(1), 102-134. https://doi.org/https://doi.org/10.1108/SO-12-2014-0028

Banomyong, R. . R., \& Supatn, N. . N. (2011). Selecting logistics providers in Thailand: A shippers' perspective. European Journal of Marketing, 45(3), 419-437. https://doi.org/10.1108/03090561111107258

Berglund, M. M., van Laarhoven, P., Sharman, G., \& Wandel, S. (1999). Third-Party Logistics: Is There a Future? The International Journal of Logistics Management, 10(1), 59-70. https://doi.org/10.1108/09574099910805932

Bolumole, Y. A. (2001). The Supply Chain Role of Third-Party Logistics Providers. The International Journal of Logistics Management, 12(2), 87-102. https://doi.org/10.1108/09574090110806316

Bolumole, Y. A. (2003). Evaluating the Supply Chain Role of Logistics Service Providers. The International Journal of Logistics Management, 14(2), 93-107. https://doi.org/10.1108/09574090310806620

Bronzo, M. (2004). Relacionamentos colaborativos em redes de suprimentos. Revista Administração de Empresas, 44, 61-73. https://doi.org/10.1590/S003475902004000500005

Busse, C., \& Wallenburg, C. M. (2011). Innovation management of logistics service providers: Foundations, review, and research agenda. International Journal of Physical Distribution \& Logistics Management, 41(2), 187-218. https://doi.org/10.1108/09600031111118558

Costa, L., Vieira, L., \& Fleury, P. F. (2002). Contract Logistics In Brazil. Booz Allen \& Hamilton Report.

Delfmann, W., Albers, S., \& Gehring, M. (2002). The impact of electronic commerce on logistics service providers. International Journal of Physical Distribution and Logistics Management, 32(3), 203-222. https://doi.org/10.1108/09600030210426539

Detoni, M. M. M. L. (2003). A evolução da indústria de prestação de serviços logísticos no Brasil: Uma análise de mercado. Universidade Federal de Santa Catarina. Universidade Federal de Santa Catarina.

Fabbe-Costes, N., Jahre, M., \& Roussat, C. (2008). Supply chain integration: the role of logistics service providers. International Journal of Productivity and Performance Management, 58(1), 71-91. https://doi.org/10.1108/17410400910921092

Fulconis, F. F., Nollet, J., \& Paché, G. (2016). Purchasing of logistical services: a new view of LSPs' proactive strategies. European Business Review, 28(4), 449-466. https://doi.org/10.1108/EBR-06-2015-0054

Fulconis, F., Paché, G., \& Roveillo, G. (2011). La prestation logistique : origines, enjeux et perspectives. (E. E. M. S.-M. \& Société., Ed.). Editions EMS - Management \& Société. Retrieved from https://hal-amu.archives-ouvertes.fr/hal-01442938

Garousi, V., \& Mantyla, M. V. (2016). A systematic literature review of literature reviews in software testing. Information and Software Technology, 80, 1339-1351. https://doi.org/10.1016/j.infsof.2016.09.002

Hamdan, A., \& (Jamie) Rogers, K. J. (2008). Evaluating the efficiency of 3PL logistics operations. International Journal of Production Economics, 113(1), 235-244. 
https://doi.org/10.1016/j.ijpe.2007.05.019

Hertz, S., \& Alfredsson, M. (2003). Strategic development of third party logistics providers. Industrial Marketing Management, 32(2), 139-149. https://doi.org/10.1016/S00198501(02)00228-6

Hosie, P., Sundarakani, B., Tan, A. W. K., \& Koźlak, A. (2012). Determinants of fifth party logistics (5PL): service providers for supply chain management. International Journal of Logistics Systems and Management, 13(3), 287.

https://doi.org/10.1504/IJLSM.2012.049700

Hsiao, H. I., Kemp, R. G. M., van der Vorst, J. G. A. J., \& Omta, S. W. F. (Onno). (2010). A classification of logistic outsourcing levels and their impact on service performance: Evidence from the food processing industry. International Journal of Production Economics, 124(1), 75-86. https://doi.org/10.1016/j.ijpe.2009.09.010

Juga, J., Pekkarinen, S., \& Kilpala, H. (2008). Strategic positioning of logistics service providers. International Journal of Logistics Research and Applications: A Leading Journal of Supply Chain Management, 11(6), 443-455. https://doi.org/10.1080/13675560802373472

Kavčič, K., Gošnik, D., Beker, I., \& Suklan, J. (2015). How does logistics outsourcing influence organisation performance? International Journal of Industrial Engineering and Management, 6(3), 101-107. Retrieved from www.iim.ftn.uns.ac.rs/ijiem_journal.php Kitchenham, B., Pretorius, R., Budgen, D., Brereton, O. P., Turner, M., Niazi, M., \& Linkman, S. (2010). Systematic literature reviews in software engineering-A tertiary study. Information and Software Technology, 52(8), 792-805. https://doi.org/10.1016/j.infsof.2010.03.006

Lai, K.-H. (2004). Service capability and performance of logistics service providers. Transportation Research Part E: Logistics and Transportation Review, 40(5), 385-399. https://doi.org/10.1016/j.tre.2004.01.002

Lai, K.-H., Ngai, E. W. ., \& Cheng, T. C. . (2004). An empirical study of supply chain performance in transport logistics. International Journal of Production Economics, 87(3), 321-331. https://doi.org/10.1016/j.ijpe.2003.08.002

Lambert, S. (2006). Do We Need a "Real" Taxonomy of e-Business Models? School of commerce research paper series. Flinders University.

Lima, L. R. R. de. (2004). A Evolução dos Prestadores de Serviços Logísticos no Brasil: O surgimento dos 4PLs. Universidade Federal de Santa Catarina.

Maia, M. D. da S. (2009). Classificação de prestadores de serviços logísticos: o caso da empresa XYV Logística Ltda. Universidade Federal do Rio Grande do Sul. Universidade Federal do Rio Grande do Sul.

Marasco, A. (2008). Third-party logistics: A literature review. International Journal of Production Economics, 113(1), 127-147. https://doi.org/10.1016/j.ijpe.2007.05.017

Michon, V. (2014). Le rôle du prestataire de services logistiques dans l'émergence des cas de mutualisation logistique concertée : application à la relation industrie -grande distribution alimentaire en France. AIX-Marseille Universite.

Mora, M. M. (2006). A Segmentação Dos Operadores Logísticos No Brasil Segundo Suas Capacitações Para Oferecer Serviços. Instituto Coppead de Administração. Universidade Federal do Rio de Janeiro. Retrieved from http://www.coppead.ufrj.br/upload/publicacoes/Dinia_Monge_More.pdf

Multaharju, S., \& Hallikas, J. (2015). Logistics service capabilities of logistics service provider. International Journal of Logistics Systems and Management, 20(1), 103. https://doi.org/10.1504/IJLSM.2015.065975

Núñez-Carballosa, A., \& Guitart-Tarrés, L. (2011). Third-party logistics providers in Spain. 
Industrial Management \& Data Systems, 111(8), 1156-1172.

https://doi.org/10.1108/02635571111170749

Papadopoulou, C., \& Macbeth, D. (1998). Third Party Logistics Evolution : Lessons from the Past. Logistics \& Supply Chain Management Conference.

Rajesh, R., Pugazhendhi, S., \& Ganesh, K. (2011). Towards taxonomy architecture of knowledge management for third-party logistics service provider. Benchmarking: An International Journal, 18(1), 42-68. https://doi.org/10.1108/14635771111109814

Razzaque, M. A., \& Sheng, C. C. (1998). Outsourcing of logistics functions: a literature survey. International Journal of Physical Distribution \& Logistics Management, 28(2), 89-107. https://doi.org/10.1108/09600039810221667

Rich, P. (1992). The Organizational Taxonomy: Definition and Design. Academy of Management Review, 17(4), 758-781. https://doi.org/10.5465/AMR.1992.4279068

Routroy, S. (2009). Selection of third party logistics provider in supply chain. International Journal of Services, Technology and Management, 12(1), 23-34. https://doi.org/10.1504/IJSTM.2009.025034

Saglietto, L. (2013). Towards a Classification of Fourth Party Logistics (4PL). Universal Journal of Industrial and Business Management, 1(3), 104-116.

https://doi.org/10.13189/ujibm.2013.010305

Saw, W. P. (2012). The Evolution of the U.S. Logistics Outsorcing Industry: An Organizational Ecology Perspective. Marketing Undergraduate Honors Thesis. University of Arkansas. Retrieved from http://scholarworks.uark.edu/mktguht/2/

Selviaridis, K., \& Spring, M. (2007). Third party logistics: a literature review and research agenda. The International Journal of Logistics Management, 18(1), 125-150. https://doi.org/10.1108/09574090710748207

Stefansson, G. (2004). Collaborative Logistics Management. The Role of Third-Party Service Providers and the Enabling Information Systems Architecture. Institutionen fur logistik och transport, Chalmers tekniska högskola,.

Stefansson, G. (2006). Collaborative logistics management and the role of third-party service providers. International Journal of Physical Distribution \& Logistics Management, 36(2), 76-92. https://doi.org/10.1108/09600030610656413

Subramanian, N., Gunasekaran, A., Papadopoulos, T., \& Nie, P. (2016). 4th party logistics service providers and industrial cluster competitiveness: Collaborative operational capabilities framework. Industrial Management and Data Systems, 116(7), 1303-1330. https://doi.org/10.1108/IMDS-06-2015-0248

Wen, C.-H., Tsai, M.-C., \& Lin, C.-H. (2011). Classification and competition analysis of air cargo logistics providers: The case of Taiwan's high-technology industry. Journal of Air Transport Management, 17(2), 106-109. https://doi.org/10.1016/j.jairtraman.2010.10.012

Yang, X. (2014). Status of Third Party Logistics - A Comprehensive Review. Journal of Logistic Management, 3(1), 17-20. https://doi.org/10.5923/j.logistics.20140301.03 dos prestadores de serviços logísticos: uma revisão de literatura. Exacta, 18(1), 101-129. https://doi.org/10.5585/Exacta.v18n1.8067. 